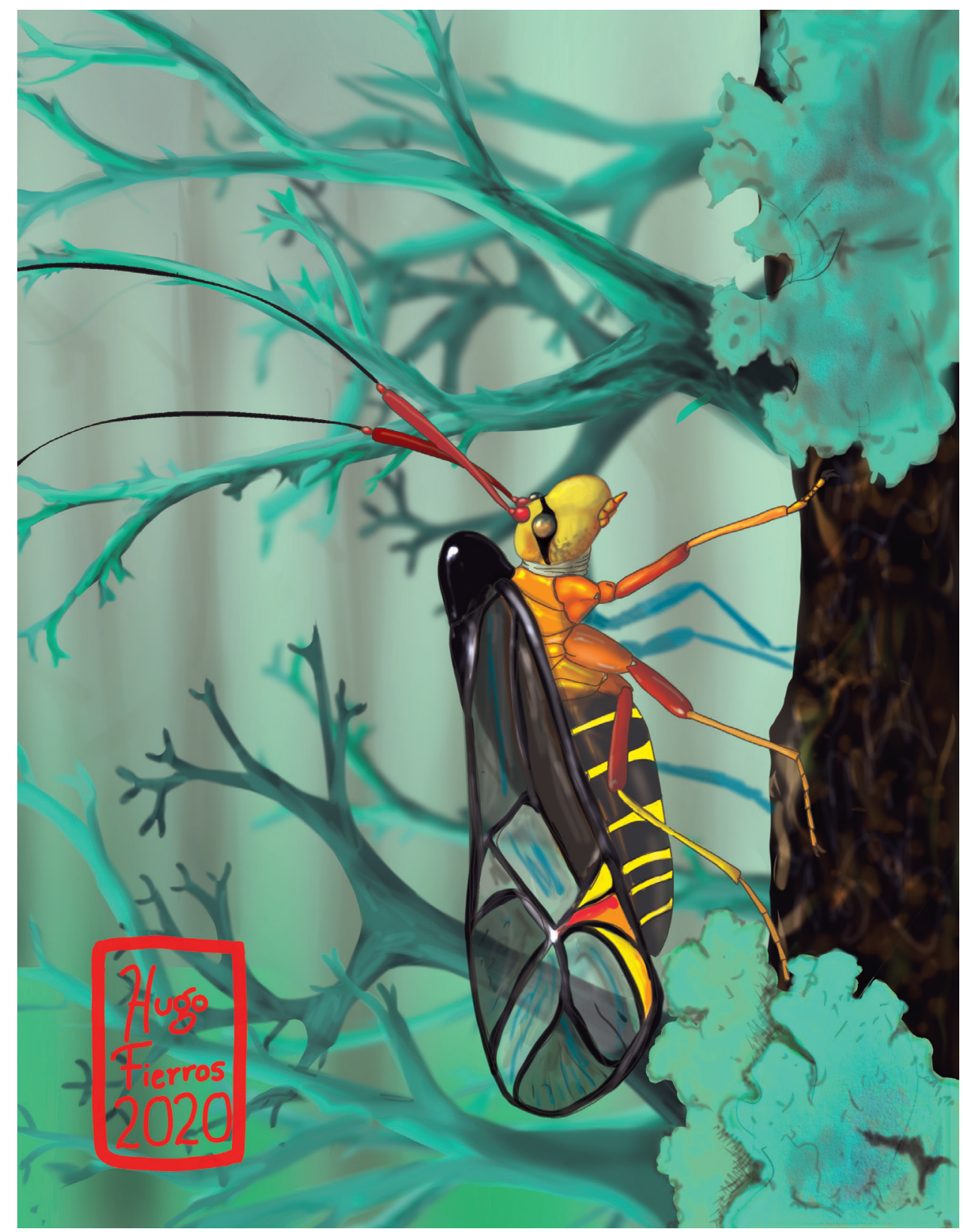

Dugesiana, Año 27, No. 2, julio 2020-diciembre 2020 segundo semestre de 2020), es una publicación semestral, editada por la Universidad de Guadalajara, a través del Centro de Estudios en Zoología, por el Centro Universitario de Ciencias Biológicas y Agropecuarias. Camino Ramón Padilla Sánchez \# 2100, Nextipac, Zapopan, Jalisco, Tel. 37771150 ext. 33218, http://148.202.248.171/dugesiana/index.php/DUG/index, glenusmx@gmail.com. Editor responsable: José Luis Navarrete-Heredia. Reserva de Derechos al Uso Exclusivo 04-2009-062310115100203, ISSN: 2007-9133, otorgados por el Instituto Nacional del Derecho de Autor. Responsable de la última actualización de este número: José Luis Navarrete-Heredia, Editor y Ana Laura González-Hernández, Asistente Editorial. Fecha de la última modificación 1 de julio 2020, con un tiraje de un ejemplar.

Las opiniones expresadas por los autores no necesariamente reflejan la postura del editor de la publicación.

Queda estrictamente prohibida la reproducción total o parcial de los contenidos e imágenes de la publicación sin previa autorización de la Universidad de Guadalajara. 


\title{
Mis recuerdos de Eduardo Rapoport
}

\author{
My memories of Eduardo Rapoport
}

\section{Gonzalo Halffter}

\author{
Instituto de Ecología, A. C., Carretera antigua a Coatepec $\mathrm{N}^{\circ}$ 351, El Haya, 91070, Xalapa, Veracruz
}

Supe de Eduardo Rapoport (Figs. 1-2) muy joven, cuando iniciaba mi tesis de biólogo en los años 50's. Mi maestro, Federico Bonet, había trabajado con Collembola y apreciaba mucho su obra, (Rapoport publicó 41 artículos sobre esos hexápodos y fauna del suelo entre 1958 y 1972). Además, me atraían sus ideas biogeográficas que planteaban que los insectos, en especial los Collembola, eran muy antiguos y su historia biogeográfica no tenía por qué ser igual a la de los mamíferos y aves. En varios trabajos, Rapoport $(1968 ; 1971)$ trató de los elementos propios de la fauna del sur (la distribución Holantártica), y como influía en la fauna Neotropical. Yo estaba elaborando las mismas ideas y encontré un apoyo en Rapoport y en Oswaldo Reig que publicó uno de sus primeros artículos sobre el tema en la obra coordinada por el primero: "Biologie de l'Amerique Australe".

En noviembre 1969, en ocasión del Cuarto Congreso Latinoamericano de Zoología, celebrado en Caracas, tuve ocasión de conocer en persona a Eduardo y a otros destacados biólogos argentinos. Además de Rapoport, recuerdo especialmente a Oswaldo Reig y a Jorge Rabinovich. A los tres el golpe militar del General Juan Carlos Onganía los había desterrado a Venezuela.

De este Congreso, tengo un recuerdo muy vivo. Presenté un trabajo resaltando la importancia de los elementos faunísticos evolucionados en el sur del Continente Americano y su solapamiento en la Zona de Transición Mexicana con los elementos de origen septentrional. Un trabajo crítico de la escuela Holarticista de Philip Darlington, entonces en pleno apogeo. No había terminado de exponer, cuando tomó la palabra una persona no muy agradable, muy enfadado y que sin más me dijo que no había entendido nada... todo lo que se sabía, estaba ya dicho en los libros de Croizat. Afortunadamente, el venezolano Carlos Machado-Allison, muy buen amigo mío, no me dejo contestar. El que hablaba era León Croizat, padre de la Pangeografía y el biogeógrafo más controvertido (innovador para otros) del siglo XX.

En el ameno libro, que por muchas razones todos deberíamos leer, de apuntes autobiográficos de Eduardo Rapoport: "Aventuras y Desventuras de un Biólogo Latinoamericano" (2015), se encuentran numerosas referencias a Croizat; entre ellas una larga relatoría entre las páginas 250 y 258 , referente a la persona y sus libros. Es de lectura obligada. Considere el lector que se critica al científico, a su manera de escribir y de relacionarse con los colegas, no a la idea de que la Tierra y la Biota evolucionan juntos.

Rapoport permanece en Caracas hasta 1971 y es allí donde con colémbolos y macetas (según relata en "Aventuras y Desventuras....") inicia su trabajo sobre diversidad y densidad de especies en el espacio. Este trabajo es el origen de la contribución más importante de Eduardo: el libro "Areografía". Antes de continuar con este libro quiero hacer un comentario sobre su manera de hacer ciencia.

$\mathrm{Al}$ hacer una revisión de la vida científica de Rapoport, varias veces interrumpida por golpes de estado y exilios, llama la atención la concentración temática de sus trabajos. Lo anterior es evidente si examinamos su tantas veces mencionada autobiografía. En distintas etapas de su vida, trabajó muy intensamente en temas muy concretos. Primero los colémbolos y la fauna del suelo (los primeros trabajos biogeográficos son con colémbolos). Seguiría lo que llama "estrategias geográficas de las especies", línea que lo llevaría a la areografía. En tercer lugar, en México, se dedicará a la ecología urbana. Un cuarto tema será la evolución de las invasiones, en realidad un aspecto concreto de la areografía. Por último, las plantas comestibles. Todos estos temas tienen relación, especialmente el segundo, tercero y cuarto, pero a cada tema dedica un esfuerzo prioritario en un determinado tiempo. Tomando en cuenta las interrupciones involuntarias y los brillantes resultados, surge la pregunta de qué parte del éxito es resultado de la capacidad para concentrar esfuerzos. Yo creo que mucha.

Volviendo a Caracas, el avance en sus trabajos sobre la distribución de las especies había cristalizado en un primer manuscrito que expuso en Princeton a Robert MacArthur (“Aventuras y Desventuras....": 86-87), ya entonces uno de los más brillantes ecólogos del siglo XX. MacArthur lo impulsó a revisar y publicar el manuscrito. En febrero 1971 surgió la posibilidad de volver a Argentina, a la Fundación Bariloche. Había enviado el texto a MacArthur, éste estaba gravemente enfermo y lo transfirieron a American Naturalist, que no lo aceptó. Rapoport siguió trabajando con el texto en español, pensando en su publicación como un libro sin las restricciones propias del artículo. Este libro es una de las contribuciones más originales de la biogeografía del siglo XX. Sobre su trabajo en este período el autor señala (2015:9): ..."la libertad con que pude trabajar, la falta de presión por la docencia, la ausencia total de burocracia y el altísimo nivel del personal fueron el aliciente necesario para poder trabajar a gusto".

"Areografía" fue terminado en 1972 y durante tres años no consiguió editor. Rapoport recurrió a mi ayuda en un buen momento. Pude recomendar la publicación de esta obra extraordinaria, pero no forzosamente comercial, a Francisco Javier Alejo, entonces Director General del Fondo de Cultura Económica, persona excepcionalmente abierta a nuevas ideas. El libro fue publicado por el Fondo en 1975, con todos los deseos (y caprichos) del autor. La edi- 
ción en inglés, de Pergamon Press, Oxford, apareció hasta 1982.

Pocas cosas son mejor evidencia de la aceptación de un bloque de ideas, que su incorporación a los grandes textos. Ningún tratado de biogeografía, aún sea tan imponente como la Biogeografía de Lomolino et al., 2010, deja de referirse a "Areografía". Con una serie de adjetivos que resaltan la obra de Rapoport, Lomolino et al, señalan que la areografía es la dinámica del área de distribución, un problema de dimensiones múltiples que afecta todos los aspectos de la biogeografía, incluyendo la conservación y la predicción de invasiones.

Con el régimen policiaco de José López Rega y el golpe militar de 1976, la Fundación Bariloche apenas sobrevivía con convenios externos. Por esos años yo había fundado en México el Instituto de Ecología (INECOL). En los años 70 's luchábamos por sacar adelante a nuestro Instituto. Antes de tener un presupuesto regular y de ser integrantes del Sistema de Centros Públicos de Investigación, buena parte de nuestros egresos dependían de proyectos que podíamos obtener. El Gobierno de la Ciudad de México (Gobierno del Distrito Federal) era miembro de la Junta de Gobierno del INECOL y se enfrentaba a los crecientes problemas ecológicos de la megalópolis que era y es la Ciudad de México.

Como se ha señalado líneas antes, conocía a Eduardo y sabía de su difícil situación. Con el deseo de contar con su colaboración, pero también con un fuerte interés en ayudar al perseguido político, lo invité a incorporarse al Instituto de Ecología y desarrollar en él una nueva rama de ecología urbana. Acepto y trabajó en el Instituto desde agosto de 1978 hasta diciembre de 1983, salvo un intermedio que pasó en Argentina. En este lapso, publicó dos libros sobre ecología urbana en la Ciudad de México y tuvo una fuerte influencia en la formación de varios ecólogos mexicanos.

La ecología urbana fue en cierta manera una continuación de sus trabajos sobre biogeografía. Que mejor escenario para estudiar la distribución que la ciudad con sus limitaciones e invasiones. Así lo vio él, y parte de la experiencia que después volcaría en el análisis de las invasiones se inicia en una estancia en Londres y en el trabajo en el Instituto de Ecología.

Una colaboración inesperada resultó de los contactos de Rapoport con jóvenes ecólogos argentinos. En varias ocasiones le comenté mi deseo de apoyar a algunos de estos jóvenes que se encontraban en dificultades, por sus ideas políticas y la persecución que el régimen militar ejercía en las Universidades. Me recomendó a dos, Carlos Montaña y Exequiel Ezcurra, éste último se encontraba en Inglaterra a donde había ido para terminar el Doctorado ante la persecución en las universidades argentinas.

Pude incorporar a Carlos Montaña y Exequiel Ezcurra al Instituto de Ecología. El Instituto ganó muchísimo con estos científicos. Carlos Montaña ha sido un brillante investigador y maestro hasta su reciente muerte. Desarrolló toda una escuela ecológica entorno a la reserva de Mapimí y tuvo una fuerte influencia como maestro en el posgrado del Instituto de Ecología.

Exequiel Ezcurra demostró desde un principio su excepcional calidad. Recién terminado el Doctorado participó en varios proyectos y así ha continuado en distintas instituciones mexicanas en las que ha realizado una muy brillante carrera. Para mí fue un apoyo incalculable en aquellos primeros años del Instituto de Ecología, pues gracias a él pu- dimos desarrollar algunos proyectos entre los que recuerdo la Reserva de la Biosfera del Pinacate y el proyecto de Dos Bocas en el Golfo de México.

La historia tiene caminos inesperados. Las dictaduras nazi-fascistas que desarrollaron en Europa los episodios más bochornosos e ignominiosos de la historia de la humanidad, así como sus continuadores en América del Sur, han favorecido-sin desearlo- a la ciencia y cultura mexicanas. Claro que no como un efecto buscado, pero no por inesperado menos importante. Me refiero a los muchos refugiados de muy alta calidad académica y en general cultural que han enriquecido las filas de las ciencias mexicanas. Es ampliamente reconocido el papel de la emigración republicana española en todos los aspectos de la cultura mexicana. Ha sido especialmente importante en la Biología. El desarrollo de la Biología en México en los años 60's y 70’s del siglo XX es resultado de la labor de los emigrados españoles a través de sus alumnos mexicanos. Menos importante en número, pero no menos importante en calidad ha sido la emigración judía. Baste recordar que la figura más destacada de la botánica mexicana, Jerzy Rzedowski, llega a México como refugiado.

Durante muchos años ha sido la cabeza de varios proyectos, especialmente de Flora del Bajío. En la Sede del Instituto en Pátzcuaro, Michoacán, ha dirigido la formación de varios doctores y realiza un brillante trabajo de investigador.

En 1983, Eduardo Rapoport hace un último regreso, éste sí definitivo de volver a la Argentina. Va a trabajar a la Fundación Bariloche. Allí continúa y desarrolla la ecología de las invasiones. Como hemos señalado, ésta tiene mucho que ver con la areografía, incluso con la ecología de las plantas y animales en ciudades como México y Londres que había examinado Rapoport.

La dinámica de las invasiones lo apasionaba. En "Aventuras y Desventuras..." comenta con qué interés leyó la obra de Elton, "The Ecology of Invasions by Animals and Plants" (1958). A partir de 1975, Rapoport publica 19 artículos sobre el tema. Muchas de sus conclusiones son de total actualidad. Por ejemplo, el efecto de la ganadería en la Argentina. Señala la desaparición de entre 171 y 427 especies de plantas asociadas a la ganadería por efecto del pisoteo, forrajeo e incluso bosteo (acumulación de estiércol) derivados de la introducción de ganado europeo.

El último gran tema al que dedica sus esfuerzos, son las plantas silvestres comestibles. A la curiosidad del biólogo, añade la del gastrónomo. Sorprende la cantidad de maleza que no aprovechamos: En Bariloche, Argentina, 1.3 toneladas por hectárea; en Coatepec, (Veracruz, México) 2.1 toneladas por hectárea.

La vida y personalidad de Eduardo Rapoport, merecen una reflexión. Fue un hombre culto, muy inteligente y bueno. Preocupado por muchas cosas e insatisfecho de otras tantas. Es imposible analizar su historia como científico y como persona sin ver las circunstancias de Latinoamérica y en especial de Argentina en el siglo XX. Todo en Eduardo iba contra el golpe militar y el totalitarismo, y buena parte de su vida la pasó huyendo de estas circunstancias.

\section{LITERATURA CITADA}

Elton, C. 1958. The Ecology of Invasions by Animals and Plants. Methuen, London. 
Lomolino, M. V., B. R. Riddle, R. J. Whittaker y J. H. Brown. 2010 Biogeography. Sinauer Associates Inc. Publishers, Sunderland, Massachusetts, USA.

Rapoport, E. H. 1968. Algunos problemas biogeográficos del Nuevo Mundo con especial referencia a la fauna Neotropical. pp. 53-110. In: C. Delamare- Debouteville y E. H. Rapoport (Eds.). Biologie de l'Amerique Australe. IV. CNRS-CNICT, Paris.

Recibido: 11 abril 2020

Aceptado: 16 abril 2020
Rapoport, E. H. 1971.The geographical distribution of Neotropical and Antarctic Collembola. Pacific Insectes Monograph, 25: 99-118.

Rapoport, E. H. 1975. Areografia: Estrategias Geográficas de las Especies. Fondo de Cultura Económica, México, D.F.

Rapoport, E. H. 1982. Areography: Geographical Strategies of Species. Peragmon Press, Oxford.

Rapoport, E. H. 2015. Aventuras y Desventuras de un Biólogo Latinoamericano. Fundación de Historia Natural Félix de Azara, Buenos Aires.

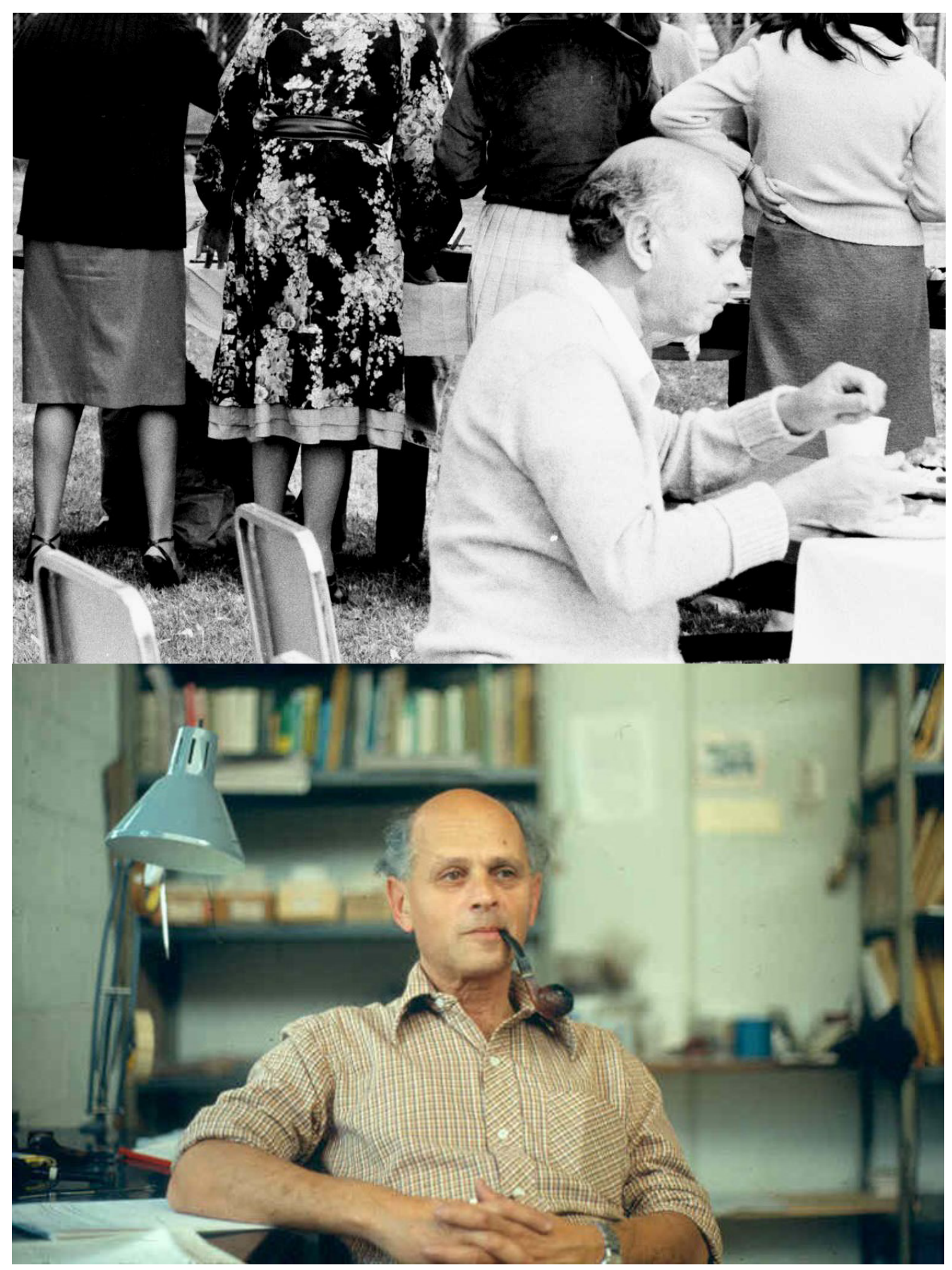

Figuras. 1-2. Eduardo Rapoport en el jardín del Museo de Historia Natural, Ciudad de México. Fotografías realizadas durante el tiempo que estuvo en el Inecol (en los años 70-80's) en la Ciudad de México. Fotografías tomadas por el Dr. Alberto González (INECOL). 